\title{
Preparación de columnas de afinidad con actina- $F$ y actina- $G$ para la obtención de proteínas de unión a actina en Plasmodium falciparum
}

\author{
Claudia Forero, Moisés Wasserman
}

\begin{abstract}
Resumen
Con el fin de obtener proteínas de unión a actina de extractos de $P$. falciparum marcados radioactivamente, se prepararon columnas de afinidad con actina- $F$ (fibrilar), actina-G (globular) y albúmina sérica bovina. Se comprobó la polimerización y se cuantificó la unión de los ligandos a la resina activada. Los resultados obtenidos demostraron una alta especificidad de las columnas. Se obtuvieron cuatro proteínas que se unieron a la columna de actina-G y 16 que se unieron a la columna de actina-F.
\end{abstract}

\section{Summary}

Affinity columns were prepared with F-actin (filaments), G-actin (monomers) and bovine serum albumin, BSA, (control) to obtain actin binding proteins from radioactively labelled Plasmodium falciparum extracts. Polymerisation was confirmed and the binding of ligands to the resin was quantified. The results show high affinity chromatography specificity as described here. Four proteins were obtained in the G-actin columns' eluted fractions and 16 in the corresponding F-actin columns' fractions.

\begin{abstract}
Aunque se conoce muy poco de las proteínas que conforman el citoesqueleto de $P$. falciparum, se ha supuesto su existencia debido a la gran flexibilidad morfológica y de movimiento que presenta el parásito tanto en su complejo ciclo de vida como en los diferentes hospederos y órganos en los cuales se desarrolla. Clínicamente, la fase asexual eritrocítica del plasmodio es fundamental, debido a que es en ella donde se manifiestan los síntomas de la enfermedad en el hospedero humano y, además, es donde el parásito es más vulnerable; esta fase se inicia con el proceso de invasión a los eritrocitos y se ha determinado que existe un movimiento de penetración el cual es totalmente dependiente del parásito $(4,5)$. Por lo anterior, se ha implicado un motor celular basado en actina-miosina $(6,7)$.
\end{abstract}

El propósito del presente trabajo fue determinar proteínas de unión a actina en extractos de esqui- zontes maduros de $P$. falciparum, para lo cual se prepararon columnas de afinidad con actina en su estado de monómero (actina-G) y en su estado de polímero (actina-F). Esta última es la estructura funcional de la actina y es en ella donde se une una gran cantidad de proteínas para modular las diversas funciones donde participa (8-11). Se utilizó la metodología descrita por Miller y col. $(12,13)$ con algunas modificaciones y se comprobó la calidad y la especificidad de las columnas antes de realizar las cromatografías con extractos de parásitos marcados metabólicamente con L-[S $\left.\mathrm{S}^{35}\right]$ metionina.

\section{Materiales y métodos}

Cultivo de parásitos: se utilizó la cepa colombiana FCB1 de $P$. falciparum, obtenida de cultivos continuos (14) en medio RPMI 1640 (Sigma), suplementado con $10 \%$ de suero humano y $5 \%$ de hematocrito de sangre $\mathrm{O}^{+}$. Los cultivos fueron 
sincronizados por el método del sorbitol (15) y se obtuvieron parasitemias entre 7 y $10 \%$ de esquizontes de 47-48 $\mathrm{h}$.

Marcación metabólica con $\mathrm{L}-\left[\mathrm{S}^{35}\right]$ metionina: se tomaron $100 \mathrm{~mL}$ de cultivo con una parasitemia $7 \%$ en anillos de $18 \mathrm{~h}$ y se lavaron dos veces con HBS (20mM Hepes/160mM NaCl, pH 7,4); luego, se resuspendió en los mismos $100 \mathrm{~mL}$ de medio RPMI libre de metionina y se adicionaron $24 \mu \mathrm{L}$ de $L-\left[S^{35}\right]$-Met (Amersham) en una concentración de $9,8 \mu \mathrm{ci} / \mu \mathrm{L}$ con una actividad específica de 1,175 $\mathrm{ci} / \mathrm{mmol}$; se dejó durante14 h y se hizo de nuevo un cambio con medio fresco al cual se le adicionó la misma cantidad de marca radioactiva que la anterior. Los parásitos se recolectaron en esquizontes cercanos a las $48 \mathrm{~h}$ postinvasión. Se determinó el porcentaje de incorporación y la actividad específica de las proteínas marcadas. Se realizó un control colocando marca radioactiva en las mismas condiciones anteriores a $50 \mathrm{~mL}$ de cultivo de eritrocitos no infectados y se llevó a cabo el mismo procedimiento que con los eritrocitos infectados, con el fin de determinar que todas las proteínas marcadas radioactivamente correspondieran a los parásitos y no a reticulocitos ni a células blancas residuales presentes en el cultivo.

Liberación y obtención de parásitos libres de eritrocitos: los cultivos de eritrocitos infectados en estadio de esquizontes, cultivados como se mencionó anteriormente, se lavaron dos veces con HBS y el precipitado se resuspendió en seis volúmenes de HBS y saponina al $0,15 \%$; posteriormente, se siguió el método de centrifugación en gradiente de densidad descrito por Wiser y Lanners (16), con algunas modificaciones, para separar las membranas de eritrocitos de los parásitos liberados. Brevemente, el método consiste en mezclar ( $\mathrm{v} / \mathrm{v}$ ) el lisado de eritrocitos con Percoll (Pharmacia) al 50\% e, inmediatamente, centrifugar a $14.000 \times$ g por $20 \mathrm{~min}$. Luego de la centrifugación, se puede observar fácilmente en la parte superior del tubo una capa blanca de membranas, la cual se retira con pipeta Pasteur y en el fondo del tubo se recuperan los parásitos libres a los cuales se les realizan tres lavados con HBS. Todos los pasos anteriores se llevaron a cabo a $4^{\circ} \mathrm{C}$. Se determinó el peso de los parásitos libres empaquetados y se resuspendieron en buffer de extracción; buffer $\mathrm{E}(5 \mathrm{mM}$ Hepes- $\mathrm{KOH}$, $\mathrm{pH} 7,5 / 0,5 \mathrm{mM}, \mathrm{Na}_{3}$ EDTA/0,5mM, Na $\mathrm{NGTT}_{3}$ / $0,05 \%$ Nonidet P-40/1 mM PMSF/0,01 mM, benzamidina- $\mathrm{HCl} / 1 \mu \mathrm{g} / \mathrm{mL}$, fenantrolina $/ 10 \mu \mathrm{g} / \mathrm{mL}$ aprotinina $/ 10 \mu \mathrm{g} / \mathrm{mL}$, leupeptina $/ 10 \mu \mathrm{g} / \mathrm{mL}$, pepstatina $A)$, en una proporción de 1/10 (p/v). En este paso se guardaron los parásitos a $-70^{\circ} \mathrm{C}$ para la posterior extracción de las proteínas.

Comprobación de la polimerización de la actina$G$ en actina- $F$ : antes de iniciar la preparación de la columna con actina $F$, se comprobó que la actina estuviera en su forma polimerizada y estable, para lo cual se realizaron experimentos previos con actina de músculo bovino (Sigma A3653), la cual fue resuspendida en buffer de baja fuerza iónica, buffer $G$ ( $5 \mathrm{mM}$ Hepes- $\mathrm{KOH}$ pH 7,5/ $0,2 \mathrm{mM} \mathrm{CaCl}_{2} / 0,2 \mathrm{mM}$ ATP) y, posteriormente, se polimerizó aumentando las concentraciones a buffer de alta fuerza iónica (50 $\mathrm{mM}$ Hepes- $\mathrm{KOH}$ / $0,1 \mathrm{M} \mathrm{KCl} / 5 \mathrm{mM} \mathrm{MgCl}_{2}$ ). Se dejó durante $1 \mathrm{~h}$ a temperatura ambiente $\mathrm{y}$, posteriormente, se utilizaron dos agentes estabilizadores de los polímeros de actina: el dimetilsuberimidato (Sigma), un entrecruzador intramolecular de los monómeros de actina (13), y la faloidina (toxina del hongo Amanita phalloides, Sigma), un agente nucleador y estabilizador de los filamentos de actina (17-19); cada uno de ellos se probó en concentraciones de uno y dos equimolar a la actina y se verificó su efectividad por medio de geles de acrilamida al $5 \%$ en condiciones denaturantes y no denaturantes.

Columna de actina F: se siguió el método descrito por Miller et al. $(12,13)$. Todos los pasos se realizaron a $4^{\circ} \mathrm{C}$ y las columnas se prepararon a un volumen final de $4 \mathrm{~mL}$. Cuidadosamente se mezclaron, $2 \mathrm{~mL}$ de Affigel 10 (BioRad) y $2 \mathrm{~mL}$ de Sepharosa Cl 6B (Pharmacia) en una columna de vidrio (BioRad), de $1 \mathrm{~cm}$ de diámetro $\times 10 \mathrm{~cm}$ de largo y se hicieron tres lavados con agua destilada desionizada y dos con buffer $F(50 \mathrm{mM}$ Hepes$\mathrm{KOH} \mathrm{pH} 7,5 / 0,1 \mathrm{M} \mathrm{KCl} / 0,2 \mathrm{mM} \mathrm{CaCl}_{2} / 0,2 \mathrm{mM}$ ATP/ $5 \mathrm{mM} \mathrm{MgCl}$ ) más $10 \mu \mathrm{g} / \mathrm{mL}$ de faloídina; este procedimiento se llevó a cabo durante $10 \mathrm{~min}$. Inmediatamente, se agregaron $2 \mathrm{~mL}$ de actina previamente polimerizada en una concentración de $2,5 \mathrm{mg} / \mathrm{mL}$ y se mezcló suavemente; luego, la 
columna se dejó durante toda la noche en un rotor de tambor (Rotator RT50 Taiyo) a mínima velocidad. Posteriormente, se dejó quieta durante 1 h y se recogió por gravedad la fracción de proteína que no se pegó. El empaquetamiento y el lavado de la columna se hicieron con buffer $\mathrm{F}$ con un flujo de 3 vol de columna/h. Para verificar el flujo de la columna, se agregó rojo de fenol disuelto en buffer $\mathrm{F}$ y se lavó hasta su total eliminación con el mismo buffer, luego, se adicionó una solución (50 mM Hepes- $\mathrm{KOH}$ pH 7,5/1 M KCl/2 mM MgCl ), con un flujo de 4 vol de columna/h. La columna se guardó con buffer $\mathrm{F}$ suplementado con $(10 \mu \mathrm{g} / \mathrm{mL}$ faloidina/ $0,02 \%$ de $\mathrm{NaN}_{3}$ ). Las cromatografías se llevaron a cabo sólo durante las tres semanas posteriores a la preparación de las columnas. A todas las fracciones recogidas, se les determinó proteína por el método de Bradford (20) y se calculó por sustracción el porcentaje de actina unido a la columna.

Columna de actina-G: la preparación de esta columna se realizó en la misma forma descrita anteriormente, pero, en este caso, debido a la gran actividad de unión de los grupos succinamida del Affigel fue necesario inactivarlos parcialmente antes de agregar la actina-G. Para ello, se incubó la mezcla de las resinas durante 90 min en buffer G. A continuación se realizaron dos lavados con el mismo buffer y se adicionaron $2 \mathrm{~mL}$ de actina bovina (Sigma) en una concentración de $3 \mathrm{mg} /$ $\mathrm{mL}$; se mezcló suavemente y se dejó durante 20 min quieta. Posteriormente, se recogió por gravedad la proteína que no se unió al affigel y se adicionaron $2 \mathrm{~mL}$ de buffer $\mathrm{G}$ más $50 \mathrm{mM}$ de etanolamina, $\mathrm{pH} 7,8$, para inactivar completamente los grupos que aún quedaban activos; se mezcló cuidadosamente y se dejó durante $3 \mathrm{~h}$, luego de las cuales se lavó con buffer $\mathrm{G}$ por gravedad. Esta columna se utilizó durante la misma semana de su preparación, una vez solamente. En todas las fracciones recogidas se cuantificó la proteína y se calculó el porcentaje de actina-G unido a la columna.

Columna de BSA: su preparación se realizó en la misma forma que la columna de actina-F, pero, se utilizó buffer $\mathrm{F}$ sin faloidina en todos los pasos. El volumen de la columna fue de $4 \mathrm{~mL}$ y se colocaron $4 \mathrm{mg} / \mathrm{mL}$ de BSA (Sigma). Debido a la mayor estabilidad de la albúmina sérica bovina, esta columna se puede almacenar hasta cuatro meses en buffer $\mathrm{F}$ con $0,02 \% \mathrm{NaN}_{3}$ y se puede reutilizar después de cada cromatografía lavándola exhaustivamente para restablecer las condiciones originales.

Obtención de las proteínas solubles de $P$. falciparum: inmediatamente antes de la ruptura de los parásitos, se adicionaron nuevamente PMSF $1 \mathrm{mM}$ e inhibidores de proteasas $(0,01 \mathrm{mM}$ benzamidina- $\mathrm{HCl} / 1 \mu \mathrm{g} / \mathrm{mL}$ fenantrolina $/ 10 \mu \mathrm{g} / \mathrm{mL}$ aprotinina $/ 10 \mu \mathrm{g} / \mathrm{mL}$ leupeptina $/ 10 \mu \mathrm{g} / \mathrm{mL}$ pepstatina $\mathrm{A}$ ). Las membranas fueron rotas con homogenizador de teflón en hielo a máxima velocidad por 10 veces. Posteriormente, se centrifugó a $10.000 \times$ g durante $20 \mathrm{~min}$ y el sobrenadante se ajustó con $2 \mathrm{mM}$ DTT/ 50 mM Hepes$\mathrm{KOH}, \mathrm{pH} 7,5$; a continuación se centrifugó a $100.000 \times g$ durante $1 \mathrm{~h}$, para remover organelos, núcleo y membranas restantes. El sobrenadante obtenido se colocó en las columnas de afinidad preparadas anteriormente.

Cromatografía de afinidad con miosina y albúmina sérica bovina, BSA: debido a la dificultad en la preparación de las columnas con actina $F$, se comprobó su efectividad y especificidad colocando $2 \mathrm{~mL}$ de una mezcla de miosina bovina y de BSA en buffer de cromatografía, bufferA ( $50 \mathrm{mM}$ Hepes$\mathrm{KOH}, \mathrm{pH} 7,5 / 2 \mathrm{mM}$ DTT/0,5 mM Na${ }_{3}$ EGTA/ 0,5 $\mathrm{mM} \mathrm{Na} \mathrm{EDTA}_{3} / 50 \mathrm{mM} \mathrm{KCl} / 0,05 \%$ Nonidet-P40/ $10 \%$ glicerol/ e inhibidores) en una concentración de $1 \mathrm{mg} / \mathrm{mL}$ de cada una de las proteínas. Antes de aplicar la mezcla anterior, la columna de actina F se lavó con 5 vol de columna de buffer $A$ con un flujo de 3 vol de columna/h. A continuación, se aplicó la muestra con un flujo menor a 1 vol de columna/h. Se lavó con buffer A, con un flujo de 2 vol de columna/h. Para determinar proteínas de unión a actina dependientes de ATP, primero, se eluyó con buffer A suplementado con $1 \mathrm{mM}$ de ATP y $3 \mathrm{mM} \mathrm{MgCl}_{2}$ a un flujo de 2 vol de columna/ $\mathrm{h}$, a continuación, se adicionó $1 \mathrm{M}$ de $\mathrm{KCl}$ al buffer anterior. Por último, se lavó la columna exhaustivamente con buffer $\mathrm{A}$, con un flujo de 3 vol de columna/h, se cuantificó la proteína a cada una de las fracciones recogidas y se realizó SDSPAGE. 
Cromatografías de afinidad de las proteínas solubles de $P$. falciparum marcadas metabólicamente con $L-\left[S^{35}\right]$-Met: se realizaron simultáneamente cromatografías en cada una de las columnas preparadas anteriormente (actina$G$, actina-F y BSA como control) utilizando una bomba peristáltica multicanal (Isco). Luego de estabilizar las columnas con buffer A, se adicionó $1 \mathrm{~mL}$ del extracto de las proteínas del citoesqueleto marcadas radioactivamente $\left(100^{\prime} 000.000 \mathrm{de} \mathrm{cpm} /\right.$ $\mathrm{mL}$ ) a cada columna. El flujo de aplicación de la muestra fue de medio vol de columna/h; luego, se lavó con buffer A con un flujo de 2 vol de columna/ h. La elusión de las proteínas unidas a las columnas se llevó a cabo en dos pasos, como se describió anteriormente para la comprobación de la especificidad y efectividad de la columna de actina-F. Las tres columnas se lavaron exhaustivamente con buffer $\mathrm{A}$ con un flujo de 3 vol de columna/ $\mathrm{h}$; la columna de actina-F se lavó por último con buffer $\mathrm{F}$ más $10 \mu \mathrm{g} / \mathrm{mL}$ faliodina y $0,02 \% \mathrm{NaN}_{3}$. Se determinaron cpm totales de cada fracción y se realizó SDS-PAGE en geles de poliacrilamida al $8 \%$ para posterior autorradiografía. Las fracciones obtenidas de las columnas de actina- $\mathrm{G}$ y de BSA, luego de aplicar la muestra (lo que no se unió) fueron recromatografiadas en la columna de actina $F$, con el propósito de reconfirmar la unión específica de las proteínas a cada una de las columnas.

Electroforesis: se realizó electroforesis denaturante en geles discontinuos de poliacrilamida, SDS-PAGE (21) y electroforesis en condiciones no denaturantes con la misma técnica pero sin SDS en los geles ni en el buffer muestra Laemmli, tampoco se adicionó $\beta$-mercaptoetanol a este último. Los geles se tiñeron con Coomassie R 250 (22) y las autorradiografías de los geles secos fueron expuestas sobre Hyperpaper ${ }^{32} S$ Secuencing (Amersham) a $-70^{\circ} \mathrm{C}$.

\section{Resultados}

Comprobación de la polimerización de la actina- $G$ en actina- $F$

Se logró la estabilización de los filamentos de actina ligados a la resina de las columnas en condiciones de baja fuerza iónica. Inicialmente se utilizaron $10 \mu \mathrm{g} / \mathrm{mL}$ de faloidina o de dimetilsuberimidato (13), pero en las condiciones de tratamiento de la actina esta concentración no fue suficiente, por esta razón, se probó uno y dos equimolar de cada uno de estos compuestos. Los resultados obtenidos en los dos casos fueron similares en las concentraciones probadas; se decidió utilizar uno equimolar de faloidina a la actina debido a que este compuesto no solo estabiliza los filamentos sino que también incrementa su polimerización; además, no modifica los sitios de unión de proteínas a la actina. La comprobación de la polimerización se llevó a cabo realizando elecroforesis denaturantes y no denaturantes. En la (figura 1A), carriles 4 y 5 , se observa que la actina polimerizada con faloidina no penetró en el gel cuando la electroforesis se llevó a cabo en condiciones no denaturantes, debido, posiblemente, a que el tamaño de los polímeros era demasiado grande, pero cuando esta misma muestra fue corrida en condiciones denaturantes (figura 1B), carriles 4 y 5, apareció de nuevo la banda correspondiente a la actina-G. Esto se debe a que la faloidina no entrecruza covalentemente los monómeros de actina, mientras que en el caso del dimetilsuberimidato, aun en condiciones denaturantes los polímeros permanecieron estables debido a que se encuentran unidos covalentemente y no entraron en el gel (figura 1C), carriles 3 y 4.

\section{Preparación de las columnas de afinidad}

\section{Columas de actina $F$}

Se prepararon seis columnas con actina $\mathrm{F}$ y los porcentajes de unión al Affigel 10 fueron entre 85,2 y $96 \%$. La especificidad de unión de proteínas a la actina $F$ se comprobó cromatografiando de una mezcla de miosina y BSA en las mismas condiciones que posteriormente se utilizaron para los extractos de proteínas de la fracción soluble de las proteínas de $P$. falciparum. En la figura 2, se observa cómo la albumina sérica bovina no se unió a la columna; la mayor parte de esta proteína salió luego de la aplicación de la muestra, carriles 2 y 3 , y el resto con los lavados posteriores, carriles 4 y 5 , en tanto que la miosina se unió a la actina. Es importante anotar que la miosina no eluyó con la adición de ATP y $\mathrm{MgCl}_{2}$, sino que se logró con la adición de $1 \mathrm{M}$ de $\mathrm{KCl}$, carril 7. Esto indicó que era posible obtener en forma diferencial proteínas de unión a actina de los parásitos, dependientes 




Figura 1. Efecto de la faloidina y del dimetilsuberimidato sobre la actina. A. Actina + faloidina en gel no denaturante; B. Actinatfaloidina en gel denaturante: 1. Marcadores de peso molecular, 2. Actina-G, 3. ActinaF, 4, 5. Actina-F+faloidina; 1 y 2 equimolar, respectivamente. C. Actina + dimeti-suberimidato (DS) en gel denaturante: 1. Marcadores de peso molecular, 2. Actina-G, 3, 4. Actina-F+(DS); 1 y 2 equimolar, respectivamente; 5,6 . Actina-G+(DS); 1 y 2 equimolar respectivamente. 8 , 9. Actina F + faloidina + DS. Gel de corrida $6 \%$ acrilamida y tinción de Coomassie. 


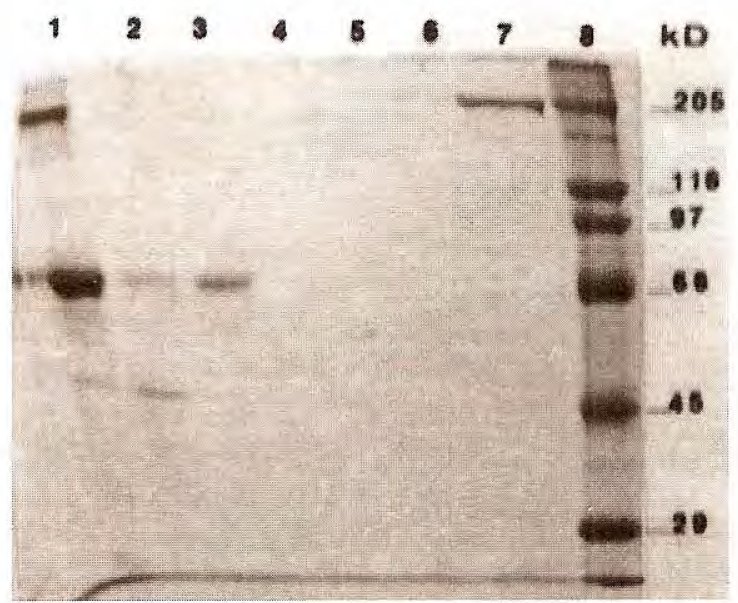

Figura 2. Control de la especificidad de unión de proteínas a la columna de actina $F$ en SDS-PAGE. 1. Mezcla de miosina y BSA antes de aplicar en la columna; 2. y 3. BSA que no se pegó en la columna y sale en la aplicación de la muestra; 4. y 5. Fracciones de lavado; 6 . Fracción eluida con $1 \mathrm{mM}$ ATP y $3 \mathrm{mM} \mathrm{MgCl}_{2} ; 7$. Miosina eluida con $1 \mathrm{mM}$ ATP, $3 \mathrm{mM}$ $\mathrm{MgCl}_{2}$ y $1 \mathrm{M} \mathrm{KCl} ; 8$. Marcadores de peso molecular; gel de corrida $8 \%$ acrilamida y tinción de Coomassie.

de ATP $/ \mathrm{MgCl}_{2}$ y otras unidas con mayor afinidad que sólo se liberan con una fuerza iónica mayor. Por medio de SDS-PAGE, se determinó que las columnas de actina $\mathrm{F}$ solo podían ser reutilizadas cinco veces como máximo, pues su capacidad de unión disminuye apreciablemente.

Columnas de actina $G$ y de BSA: el porcentaje de actina $G$ unido a la columna fue de $54 \%$ y los porcentajes de BSA unidos a las columnas fueron de 72 a $75 \%$. Para los experimentos realizados, estas dos columnas fueron los controles que determinaron la especificidad de la unión de las proteínas a las columnas de actina- $F$ y se utilizaron para las cromatografías de los extractos radioactivos, que fueron los que sirvieron para realizar un análisis cuantitativo y cualitativo de las proteínas de unión a la actina $\mathrm{F}$ y a la actina $\mathrm{G}$.

\section{Proteínas obtenidas luego de las cromato- grafías de afinidad}

Se determinó la radioactividad en cpm de cada una de las fracciones obtenidas en las tres columnas: actina $\mathrm{G}$, actina F y BSA, luego de la cromatografía de $1 \mathrm{~mL}$ del extracto de las proteínas solubilizadas de los parásitos, que contenía $100^{\prime} 000.000 \mathrm{cpm}$. Como se describió en materiales y métodos, la muestra se aplicó en las tres columnas simultáneamente y con la misma velocidad de flujo en cada una de ellas, los volúmenes de elusión fueron los mismos en cada caso; de esta forma, se pudo determinar cuantitativamente (cpm de cada fracción) y cualitativamente por medio de electroforesis y autorradiografía, las proteínas que se unieron a cada columna. Con base en estos resultados, se concluyó que $2,87 \%$ del extracto total de las proteínas cromatografiadas se unieron a la columna de actina $F$ y solo $0,91 \%$ a la columna de actina $G$. En las autoradiografías de las fracciones concentradas, se determinó la presencia de 10 proteínas de unión a la actina- $F$ que eluyeron con ATP/ $\mathrm{MgCl}_{2}$ y 16 (figura $3 \mathrm{~A}$ ) carril 2 y 16 que eluyeron con la adición de $\mathrm{KCl}$ (figura $3 A)$, carril3. En la columna de actina $G$, dos proteínas eluyeron con $\mathrm{ATP} / \mathrm{MgCl}_{2}$ (figura $3 \mathrm{~B}$ ), carril 2, y dos eluyeron con la adición de $\mathrm{KCl}$ (figura 3B), carril 3. Por el contrario, en la columna control de BSA no hubo unión de proteínas, confirmando una alta especificidad de unión de las proteínas a las columnas de actina $G$ y actina $F$.

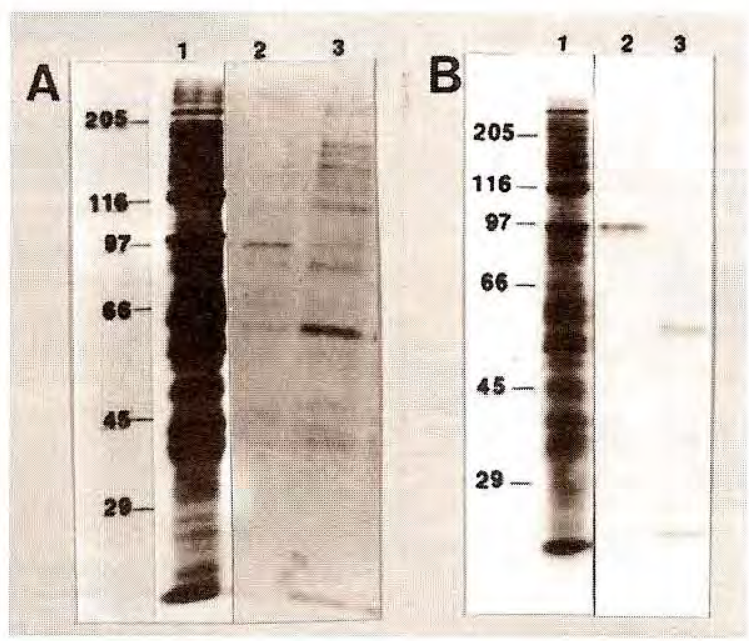

Figura 3. Autorradiografías de las fracciones obtenidas de las cromatografías de afinidad. A. Columna de actina F. B. Columna de actina G. 1. Extracto de esquizontes antes de aplicar en la columna, 2. Proteínas eluidas con ATP y $\mathrm{MgCl}_{2}$, 3. Proteínas eluidas con ATP, $\mathrm{MgCl}_{2}$ y $\mathrm{KCl}$. Gel de corrida, $8 \%$ acrilamida, exposición sobre Hyperpaper ${ }^{35} S$ sequencing (Amersham). 


\section{Discusión}

La preparación de las columnas de afinidad con actina-F es complicada debido a la alta viscosidad de las soluciones que contienen filamentos de actina. Por esta razón, la cantidad de actina que se pega a las columnas es crítica y se debe comprobar el flujo de la columna para evitar posteriores problemas durante las cromatografías, debidos a la acumulación de agregados de proteínas que luego se liberan con la adición de los buffers de alta fuerza iónica y que pueden confundirse con las proteínas que se unen específicamente a la actina. Aunque los dos compuestos utilizados para estabilizar los filamentos mostraron, por electroforesis, ser efectivos, se decidió el uso de faloidina debido a las ventajas adicionales que se mencionaron anteriormente.

Los porcentajes de actina $F$, actina $G$ y BSA ligados al Affigel 10 fueron muy similares a los informados por Miller et al. (13) y se logró obtener columnas con flujos adecuados para las cromatografías realizadas. Se comprobó la alta especificidad de la columna de actina- $F$, cromatografiando una mezcla de dos proteínas: una de reconocida capacidad de unión a la actina (miosina) y otra que no presenta ninguna afinidad a ella (BSA); también se comprobó que se obtenía una alta recuperación de las proteínas luego de la cromatografía (figura 2), carriles 1 y 7 , lo cual resultó favorable cuando se realizaron las cromatografías con los extractos de los parásitos, debido al bajo porcentaje de proteínas de unión a actina presentes.

El comportamiento de unión de la mayoría de las proteínas a la columna de actina- $F$ fue igual al observado con la miosina de músculo bovino que se utilizó como control, es decir, sólo fueron liberadas de la columna con la adición $1 \mathrm{M}$ de $\mathrm{KCl}$. Este mismo resultado fue observado por Miller y Alberts (12), al cromatografiar extractos de molleja de pollo en columnas de actina-F. Se obtuvieron cuatro proteínas de unión a la actina-G, dos con pesos moleculares de 115 y $111 \mathrm{kDa}$ que eluyeron con el buffer de baja fuerza iónica, las cuales también se observaron en la misma fracción de la columna de actina- $F$ y dos que eluyeron con la adición de $1 \mathrm{M}$ de $\mathrm{KCl}$, una de $55 \mathrm{kDa}$ y otra de 13 $\mathrm{kDa}$. La primera de éstas también está presente en la fracción eluida de la columna de actina-F. Por su peso molecular, coincide con la actina ubicuitina del parásito informada por Field et al. (6). Posiblemente, la proteína de $13 \mathrm{kDa}$ sea profilina, una proteína que se une a la actina-G y que se ha encontrado en la mayoría de las células eucariotas donde se ha buscado. Esta proteína cumple un papel muy importante al regular la cinética de polimerización de la actina a través de fosfolípidos de membrana (23-25). Claramente se observó una muy baja obtención de proteínas de unión a la actina-G en comparación con las obtenidas en las columnas con actina-F; probablemente esto se deba a que las condiciones en las cuales se lleva a cabo la preparación de los extractos y, posteriormente las cromatografías, favorecen la forma monomérica de la actina endógena del parásito $\mathrm{y}$, por tanto, se deben formar complejos con proteínas de unión a actina$G$ que impiden que se unan a la actina de la columna. Adicionalmente, debe existir una competencia entre la actina endógena libre y proteínas de unión a actina-G del parásito por la actina de la columna.

De los extractos cromatografiados en las columnas de actina- $F$, se obtuvo un total de 16 proteínas que marcaron radioactivamente, lo cual confirma, que provenían de los parásitos y no de los eritrocitos. Sus pesos moleculares comprenden un rango de 260 a $13 \mathrm{kDa}$. La cantidad obtenida es suficiente para realizar su identificación por medio de anticuerpos específicos en pruebas de Inmunoblot y es posible obtener las cantidades requeridas para producir anticuerpos policlonales o monoclonales. Esta metodología permite obtener directamente de extractos crudos, en un solo paso, proteínas de unión a actina sólo por su capacidad de unión a esa molécula o a una fibra polimérica de la misma.

\section{Agradecimientos}

El presente trabajo fue financiado por el Instituto Nacional de Salud y por el Instituto Colombiano para el Desarrollo de la Ciencia y la Tecnología Francisco José de Caldas, Colciencias. 


\section{Referencias}

1. Bannister LH, Mitchell GH. The role of the cytoskeleton in Plasmodium falciparum merozoite biology: an electron-microscopic view. Ann Trop Med Parasitol 1995;89:105-11.

2. Tilney LG, Tilney MS. The cytoskeleton of protozoan parasites. Curr Opinion Cell Biol 1996;8:43-8.

3. Bannister LH, Dluzewski AR. The ultraestructure of red cell invasion in malaria infections: a review. Blood Cells 1990;16:257-292.

4. Aikawa M, Miller LH, Johnson J, Rabbege J. Erythrocyte entry by malarial parasites. J Cell Biol 1978; 77:72-8.

5. Dluzewski AR, Fryer PR, Griffiths S, Wilson RJM, Gratzer WB. Red cell membrane protein distribution during malarial invasion. J Cell Sci 1989;92:691-9.

7. Field SJ, Pinder JC, Clough B, Dluzewski AR, Wilson RMJ, Gratzer WB. Actin in the merozoite of the malaria parasite, Plasmodium falciparum. Cell Motil Citosk 1993;25:43-8.

8. Webb S. E, Fowler RE, O'Shaughnessy C, Pinder JC, Dluzewski AR, Gratzer WB, et al. Contractile protein system in the asexual stages of the malaria parasite Plasmodium falciparum. Parasitology 1996; 112:451-57.

9. Bremer A, Aebi U. The structure of the f-actin filament and the actin molecule. Curr Opinion Cell Biol 1992;4: 20-6.

10. Bretscher A. Microfilament structure and function in the cortical cytoskeleton. Ann Rev Cell Biol 1991;7: 337-74.
11. Carlier MF. Actin: protein structure and filament dynamics. J Biol Chem 1991;266:1-4.

12. Hartwig JH, Kwiatkowski DJ. Actin-binding proteins. Curr Opin Cell Biol 1991;3:87-97.

13. Miller KG, Alberts BM. F-actin affinity chromatography: technique for isolating previously unidentified actin-binding proteins. Proc Natl Acad Sci USA 1989;86:4808-12.

14. Miller KG, Field CM, Alberts BM, Kellog DR. Use of actin filament and microtubule affinity chromatography to identify proteins that bind to the cytoskeleton. Methods Enzymol 1991;196:303-19.

15. Trager W, Jensen JB. Human malaria parasites in continuous culture. Science 1976;193:673-75.

16. Lambros C, Vanderberg JP. Synchronization of Plasmodium falciparum intraerythrocytic stages in culture. J Parasitol 1979;65:418-20.

17. Wiser MF, Lanners HN. Rapid transport of the acidic phosphoproteins of parasite to the host membrane using a miniaturized fractionation procedure. Parasitol Res 1992;78:193-200.

18. Estes JE, Selden LA, Gershman LC. Mechanism of action of phalloidin on the polymerization of muscle actin. Biochemistry 1981;20:708-12.

19. Coluccio LM, Tilney G. Phalloidin enhances actin assembly by preventing monomer dissociation. J Cell Biol 1984;99:529-35.

20. Cooper JA. Effects of cytochalasin and phalloidin on actin. J Cell Biol 1987;105:1473-78.

21. Bradford MM. A rapid and a sensitive method for the quantitation microgram quantities of protein utilizing the principle of protein dye binding. Anal Biochem 1976; 72:255-60. 